\title{
History of Medicine in the Baltic Sea region: Introductory remarks by the Editor
}

\begin{abstract}
A new "Hanseatic League", "a global hotspot for health", "one of the most innovative science macro-regions in the world"? In the fields of life science and technology, politicians and managers of current large research projects describe the Baltic Sea region as a hub of cutting-edge research. How did these images emerge? Although several research programs have been established to foster research on this territory, surprisingly few publications deal thoroughly with "Baltic" networks in medicine and their impact for the production and spread of knowledge. The network "Bridging the Baltic: Medicine in the Baltic Sea Region" brings together researchers who currently work on aspects of medical history in the Baltic Sea region to illuminate currents of ideas and areas of cooperation and conflict. With participants from all corners of the Baltic Sea area, we have so far had four symposia in Lund 2014, Düsseldorf 2019, online (due to Covid-19) 2021, and most recently Riga 2021. ${ }^{1}$ These meetings have been characterized by interdisciplinarity with speakers from different fields, such as historians, physicians, geographers, ethnologists and scholars of literature studies. Following the volume "Explorations in Baltic Medical
\end{abstract}

1 Bridging the Baltic I, Lund University October 8-10, 2014: Bridging the Baltic: Transfers of medical knowledge in the Baltic Sea region 1850-2000 (a Marcus Wallenberg symposium). Bridging the Baltic II, Heinrich-Heine-University Düsseldorf March 28-30, 2019: Scandinavian-German contacts in medicine and the sciences during the Cold War (cooperation with Leopoldina). Bridging the Baltic III, Zoom March 18-19, 2021: Medicine in the Baltic Sea region: Networks, Transfers, Consequences. Bridging the Baltic IV, August 21-22, 2021: Medicine in the Baltic Sea region. At the moment we are planning two Bridging the Baltic symposia to take place in 2022. 
History 1850-2015"2 this special issue of Acta medico-historica Rigensia contains a selection of the papers presented at recent "Bridging the Baltic" symposia.

One main theme of the network is about how the circulation of knowledge in medicine played out during the Cold War. How did science exchange in medicine work across the Iron curtain? Three articles in this issue shed light on different aspects.

First, using the example of Pomeranian Medical University (PUM) of Szczecin, founded in 1948, Joanna Nieznanowska (Szczecin) highlights challenges the new medical school in the late 1940's and early 1950's faced in strategies to promote international contacts. She shows that Szczecin's post-1945 status in Poland and Europe was a major factor behind the Stalinist state government's desire to use PUM in political propaganda strategies.

Second, Anne Oommen Halbach (Düsseldorf), reconstructs the cooperations during the 1970's of the East and West German associations with Polish scientists to commemorate the Polish-Jewish paediatrician, pedagogue and writer Janusz Korczak (1878/79-1942) and the "competing communities" of memory. The article illuminates how Korczak associations were founded in both German states under the umbrella of different institutions and divergent political influences.

Third, Alexandra Nicolaidis, Peter Nilsson and David Dunér (Lund) investigate the network of Alexandra Kollontai (1872-1952), the Soviet ambassador to Sweden from 1930 to 1945, with an emphasis on the three Swedish female physicians Ada Nilsson (1872-1964), Andrea Andreen (1888-1972) and Nanna Svartz (1890-1986).

The next section includes two case studies on transfer of knowledge between Sweden and Germany and Sweden and Denmark at the turn of the 20th century.

The paper by Yvonne Gavallér (Düsseldorf) discusses therapeutics of neurasthenia around 1900.

Based on the analysis of transfers and an evaluation of medical objects, she reconstructs the entanglement between Germany and Sweden on both a scientific and societal level as well as their impact on the therapy of the disease.

2 Nils Hansson and Jonatan Wistrand, eds., Explorations in Medical History in the Baltic Sea region 1850-2015 (Rochester, NY: University of Rochester Press, 2019). 
In the following article, Kristin Halverson (Stockholm) takes a closer look at two examples of the social strategies used by Danish surgical instrument maker Camillus Nyrop and his Swedish colleague, Max Stille, during the last three decades of the $19^{\text {th }}$ century. On a more general level, Halverson's study promotes our understanding of the relations between technical professions and physicians in the transfers of knowledge in medicine.

At our network symposia at least one section is usually devoted to current challenges in medicine in northern Europe. At the Riga symposium in August 2021, for instance, experts from Estonia, Latvia and Sweden discussed recent developments in the field of e-health. In his article, Steffen Fleßa (Greifswald) initiates a debate about innovations in healthcare of peripheral regions, which he, zooming in on Greifswald, elaborates on with a focus on economic strength and potential, demography and mobility.

From the beginning, it has been our aim in this network to not only present and discuss ongoing research related to the over-arching topic, but also to establish a cooperation on teaching of history of medicine. One such example is a seminar where students create and present scientific posters to shed light on collaboration and conflict in "Baltic Sea" medicine. This course is presented in a commentary by Felicitas Söhner, Yvonne Gavallér and Nils Hansson.

The special issue is directed to a wide readership, including students, physicians, historians, and laypersons with an interest in medicine in the Baltic Sea region. We are grateful to the German Research Foundation (DFG) for funding our symposia 2021-2022 and to the European Association for the History of Medicine and Health (EAHMH) for supporting the Bridging the Baltic network. We are also indebted to Juris Salaks, Ieva Lībiete and Ineta Lipša for kind assistance in preparing the issue.

Düsseldorf,

September 2021 